cognitivos. En efecto, para Jakubecki el conocimiento de sí, junto con el conocimiento de la voluntad de Dios, juega como fundamento para pensar las distintas manifestaciones del pecado. La propuesta consiste en mostrar cómo las distinciones del concepto de pecado se corresponden con modos de descuidos que el hombre comete al conocerse o conocer la voluntad de Dios.

Por su parte, Gustavo Fernández Walker nos ofrece en su trabajo una amena descripción del Libro de la Manzana, comentando, asimismo, la recepción que tuvo el texto en el Occidente Latino. Para el autor la escena final de la obra donde se muestra a un Aristóteles moribundo frente a sus alumnos expresa un tratamiento del cuidado de sí a partir de la búsqueda de la buenaventura mediante la filosofía. Por último, Marcela Borelli (capítulo 15), examina el cuida270 । do de sí en la obra de Petrarca.A los ojos de la especialista, Petrarca se sirve tanto de los modelos monásticos como de las enseñanzas de los antiguos para edificar un modo de cuidado de sí que no se reduce a un ascetismo espiritual sino que también abarca el cuidado del cuerpo.

En conclusión, este libro ofrece una seductora invitación a recorrer algunos de los textos filosóficos más destacadas del pensamiento antiguo y medieval desde la pregunta por el conocimiento y el cuidado de sí y del otro, cuestión sobre la que, por cierto, no abunda material en la literatura especializada en español. Tal vez, uno de los aciertos de esta obra, vista en su conjunto, sea el poder introducir al lector inexperto a esta temática como asimismo conformar al especialista a partir del análisis de las fuentes y de la sistematización de bibliografia específica que brinda cada estudio.

GASTÓN DELBONO

$U B A$

\title{
Lotario de Segni, De la miseria de la condición humana o Del desprecio del mundo, edición del texto, versión y anotación de Mariana Andujar y otros, Buenos Aires, Vermis Immortalis, 2018, 243 pp.
}

Con su sugestiva doble titulación hum ana o Del desprecio del mundo, opúsculo que Lotario de Segni escribió algún tiempo antes de convertirse en el papa Inocencio III (esto es, en algún momento anterior a 1198), sobresale entre los muchos otros tratados me- dievales que contribuyeron a hacer del contemptus mundi y de la miseria humane conditionis un tópico en sí mismo.Y a tal punto sobresale, que se consolidó como su representante durante el Renacimiento italiano, época en la que, paradójicamente -o no tanto- el tema de la dignidad humana ocupaba el centro de 
las reflexiones filosóficas. Por este motivo de carácter doctrinal y por el grato desafio que supone traducir el particular estilo literario de este autor, pródigo en aliteraciones y otros recursos retóricos, es que el equipo de lectura coordinado por Antonio Tursi y conformado, además, por Mariana Andujar, Bernardo Antico, María Eugenia Boni, Ricardo G. Caputo, Emanuel Feoli, Diego G. Mejuto, Patricia Musset, Mariano Pérez Carrasco y Georgina Olivetto eligió esta obra para que fuera su opera prima.

Para la misma, según explican en las páginas que presentan el libro, han establecido una versión propia del texto latino, siguiendo, no obstante, la edición de Michele Maccarrone en primer lugar y optando por variantes tomadas de su aparato crítico o de otras ediciones disponibles. Un detalle no menor es que las razones de cada una de estas elecciones han sido señaladas y la mayor parte de ellas, incluso, explicadas en su correspondiente nota al pie.

A la ya mencionada presentación le siguen dos breves estudios. El primero repasa el tema de la miseria del mundo desde su origen en una epístola de Euquerio de Lyon († c. 450), su tránsito por el mundo medieval y, finalmente, su gravitación en el Quattrocento, cuando más contrasta con el tópico de la dignitas hominis, tan caro al humanismo italiano. El segundo estudio no es tanto una biografia de Lotario de Segni, como podría parecer a primera vista, cuanto una ponderación del talante intelectual de Inocencio III y de su importancia en la vida política de su tiempo. Cierra esta primera parte del libro un apéndice bibliográfico que, además de consignar las principales piezas de lectura complementaria, da cuenta de las restantes ediciones y traducciones del De miseria humanae con- ditionis y del Sermón IX, traducido al castellano aquí por primera vez.

Lotario comienza el prólogo de su opúsculo con una dedicatoria al cardenal Pedro Galloccia. Allí le comenta que "para reprimir la soberbia, que es la madre de todos los vicios" decidió describir "la vileza de la condición humana", a la vez que le deja saber que tiene en mente redactar otro ensayo que verse sobre la dignidad humana para que por él "se exalte al humilde" (p. 39). El hecho de que más de un siglo después Francesco Petrarca dijera en sus Seniles que Lotario defraudó a la posteridad al no escribir este complemento (XVI, 9) es más que una curiosidad literaria: es prueba de la continuidad, muchas veces desdeñada, entre el espíritu humanista del siglo XII y el del siglo XIV.

El contenido y la organización de los tres libros que componen el De la miseria de la condición humana o Del desprecio del mundo responde a la necesidad del autor de dar cuenta de todos y cada uno de los aspectos de la vida del ser humano en su estado lapso, aspectos de los que el libro I es una especie de resumen. Así pues, empezando por la vileza de la materia y terminando con una advertencia sobre los injustos castigos y absoluciones, en este primer libro Lotario recorre temas vinculados al "miserable ingreso de la condición humana” ( $\mathrm{p}$. 43) sin privarse de hacer acotaciones de índole médica-como en el capítulo IV, que trata de los alimentos de los que "se nutre el feto en el útero", o en el VI, acerca de los dolores del parto- o de índole sociopolítica y moral, hablando de ricos y pobres (c. XV), de siervos y señores (c. XVI), de la compasión (c. XXV) o sencillamente de buenos y malos (c. XVIII). Según el mismo Lotario, su intención en la segunda parte es discu- 
rrir sobre el progreso de la condición humana en el transcurso de la vida ( $\mathrm{p}$. 43). Como resultado, nos encontramos con un libro II que bien puede leerse como un tratado ético, más aún, uno sobre los pecados capitales, aunque según un heptálogo más bien propio: codicia, avaricia, gula, lujuria, ambición, soberbia y arrogancia. El libro III es el más oscuro y -quizá justamente por elloel más atractivo desde el punto de vista del tópico mismo. En él abundan las referencias escatológicas en cualquiera de sus dos acepciones. Un pasaje que puede dar buena idea tanto del contenido como de la forma literaria tan propia del autor es aquel que se halla en el capítulo IV, "De la podredumbre de los cadáveres”. En efecto, allí se lee: "El hombre ha sido concebido a partir de la sangre putrefacta por el ardor del deseo, y a su cadáver asisten, finalmente, como cortejo fúnebre, gusanos. Estando vivo engendró piojos y lombrices; muerto engendrará gusanos y moscas; vivo produjo excremento y vómito; muerto producirá podredumbre y hedor [...] Aquel a quien era muy grato abrazar en vida, será molesto ver en su muerte" (p. 187). Ya en los capítulos finales, la pluma de Lotario le cede cada vez más lugar a las citas bíblicas, de seguro confiando en que ellas describen mucho mejor que él las angustias y penas de los condenados, el fuego del infierno $\mathrm{y}$, desde luego, el temible juicio divino con el que se cierra su obra.

Completa esta intensiva excursión por las desdichas humanas el Sermon IX, "Del pesado yugo sobre los hijos de Adán en el ingreso, el progreso y el egreso y de la ocupación honesta y útil", que oficia como una especie de epítome del texto principal.

En lo que concierne a la versión castellana, se destaca ante todo el esfuerzo que supone una traducción conjunta y el muy buen resultado que, en este caso en particular, ha tenido dicha experiencia: un texto circunspecto que refleja la gravedad del contenido, por una parte, y un texto fluido, homogéneo y consistente en cuanto a la terminología, por otra. En más de una oportunidad, el equipo se ha inclinado por palabras o giros que, aunque están cayendo en desuso, descubren mejor que cualesquiera otros el original latino, de modo que no solo logró cumplir con su objetivo explícito de reflejar lo más fielmente posible este extraordinario texto (p. 8), sino también recuperar la riqueza cada vez menos aprovechada de nuestro propio vocabulario. Con todo, ello no ha sido impedimento para que se apartaran de la mera literalidad toda vez que fuera conveniente. Así, por ejemplo, optaron por un "reconocido" ante la expresión "exceptus genibus", que literalmente debería traducirse como "depositado en las rodillas", y alude a la práctica de colocar al neonato en las rodillas del padre a fin de que lo identifique como hijo, tal como se explica en la nota 7 (p. 98).

Respecto de la edición, lo primero que se aprecia y se debe agradecer es que la edición no solo sea bilingüe sino, especialmente, que tenga ambos textos confrontados, formato que -parafraseando al propio Inocencio III- a quien no lee latín, mínimamente afecta; y a quien sí lo lee, máximamente aprovecha (cf. p. 26). Otro detalle que no sería justo pasar por alto es la inclusión las ilustraciones más representativas del Ms. París, BnF, Fr. 20029, que contiene al mismo De contemptu mundi. La última de ellas, aunque proviene de otro códice, se trata precisamente de ese vermis immortalis del que Lotario habla en más de una opor- 
tunidad y que, además, ha servido de nombre a la editorial. Así, este pequeño gesto es en realidad una muestra de que nada en este libro, ni siquiera el guiño verde en la solapa posterior, ha sido librado al azar.

Como medievalistas, no queda sino celebrar esta primera publicación del equipo de traductores coordinado por
A. Tursi, deseando que continúen su labor y no permitan que a la decepción de Petrarca por no leer más de Lotario (p. 14), se le sume la nuestra por no leer más de ellos.

NATALIA JAKUBECKI

$U B A$

CONICET

\section{Ricardo Gutiérrez Aguilar, Deuda y legado de la Filosofía de la Historia de Schiller, Barcelona, Herder, 2018, 432 pp.}

A los efectos de enmarcar el propuesta de su autor ha de señalarse que el 26 de mayo de 1789 Schiller pronuncia en Jena su Lección inaugural como docente titulada: ¿Qué viene a significar y para qué se estudia Historia Universal? En esta época, Schiller está leyendo de Kant Ideas para una historia universal en clave cosmopolita y responde a las posiciones de este último. En este marco su Lección analiza dos aspectos centrales: la fuente documental y al propio historiador que la interpreta. Con respecto a las fuentes defiende la misma causalidad que la Naturaleza le garantiza a la Ciencia. En cuanto al oficio del historiador, sus tópicos centrales son la motivación y el reino de la Libertad. De este modo, cientificidad y estética confluyen en el análisis schilleriano de la historia. Con este hilo conductor despliega Ricardo Gutiérrez Aguilar su análisis de la Filosofia de la Historia de Schiller. Ya desde la introducción del libro señala la importancia que tiene el pasado y la posibilidad de su recuperación (pp. 11-14). El objeto de este extenso y erudito estudio es presentar al lector los dos conceptos centrales que vertebran el análisis: el documento-fuente historiográfica y la interpretación del historiador (p. 15). En lo que sigue analizamos esta doble articulación en las cuatro partes en que se divide el libro.

En la primera parte se reconstruyen los tópicos de la lección inaugural de Schiller en la cual se destaca su análisis del progreso (p. 30). A partir de aquí el vínculo con Kant es presentado por el autor siguiendo el hilo conductor de la noción de gratitud (pp. 31-38). En la sección 1.1. se profundiza esta comparación entre ambas filosofias de la historia. Es así como Schiller desarrolla en su Lección inaugural los principios normativos y descriptivos en la historia y la 